\title{
Effect of Feet Reflexology on Autism Symptoms and Constipation in Children with Autistic Spectrum Disorder
}

\author{
Azza Abdalla Ghoneim $^{1 *} \quad$ Shimaa AbdElhady Badawy ${ }^{1} \quad$ Seham Farouk Ismael Mahedy ${ }^{2}$ \\ 1.Pediatric Nursing Department, Faculty of Nursing, Menoufia University, Egypt \\ 2.Assistant Professor in Department of Health Sciences Sports, College of Sports Education, Minya University
}

\begin{abstract}
The autistic Spectrum Disorder represents specific distinguishable symptoms that have frequent concurrent conditions and constipation is the most frequent. It requires an effective non-disturbing management. Reflexology is a widely used technique and documented as a useful nursing intervention. This study aimed to determine the effect of feet reflexology on autism symptoms and constipation in children with ASD. Subject and Methods: a quasi-experimental design was utilized and it conducted at the psychiatric outpatient clinic, Menoufia University hospital. A purposive sample of 30 children was recruited. Two instruments were utilized: Autism Treatment Evaluation Checklist (ATEC) and Constipation Assessment Questionnaire (CAQ). Results: children had lower mean scores and severity of autism symptoms on post-intervention compared to pre-intervention speech/communication, sociability, sensory/cognitive, health/physical/behavior subdomains and the total ATEC score. The mean total score of constipation symptoms was lower on post-intervention compared to pre-intervention $(35.93 \pm 16.04,40.23 \pm 17.51$ respectively) and there was a significant correlation $(\mathrm{R}=0.858)$ at the 0.01 level of significance between constipation and the severity of autism symptoms on post-intervention. Conclusion: the study concluded that autistic children exposed to feet reflexology experienced lower mean scores of autism symptoms and less severity of constipation compared to pre reflexology massage. There was a significant correlation between constipation and the severity of autism symptoms on post-intervention. Recommendation: Feet reflexology should be integrated as a part of routine daily care for autistic children and courses that enable nurses to obtain a certification in reflexology are needed.
\end{abstract}

Keywords: Autism Symptoms, Constipation, Reflexology

DOI: $10.7176 / \mathrm{JHMN} / 60-09$

Publication date:March $31^{\text {st }} 2019$

\section{Introduction}

Autistic Spectrum Disorder (ASD) is a lifelong disability affects the overall health of children that impose a burden on the family and health care system (Fletcher, et al., 2012). Recently, the American Psychiatric Association (2013) clarified that ASD encompassed numerous types including atypical autism, childhood disintegrative disorders, pervasive developmental disorder not otherwise specified, and Asperger's syndrome.

ASD is the second most common developmental disability among children and there is a growing rate of newly diagnosed children with autism ranges from 10-17\% each year (Iannuzzi, et al., 2018). It affects 1 in 59 American children and four folds more prevalent among boys than girls (Baio et al., 2018). However, the estimated number of autistic children in Egypt was 140.000 children and approximately, affects one child in 870 children (Haffiz, 2007; Elbahnasawy, 2011).

An autistic spectrum disorder is a complex developmental disorder of the brain that is characterized by a broad range and severity of intellectual and behavioural deficits (Hockenberry et al., 2013; American Psychiatric Association, 2013). Autism symptoms display specific distinguishable symptoms. The dominant feature of ASD is the social communication dysfunctions (Park et al., 2016) which include impairment of the verbal and nonverbal communication. Another hallmark characteristic of ASD is a repetitive stereotyped behavior (Kotagal, Broomall, 2012).

Furthermore, there are numerous health conditions frequently concurrent with autism. Gastrointestinal symptoms have been reported in frequent studies with a wide prevalence ranged from $9 \%$ to $91 \%$ which relies on the severity of gastrointestinal dysfunction (Buie et al., 2010; Ghoneim, 2018). Among these symptoms, constipation is the most frequent gastrointestinal symptom (Ibrahim et al., 2009; Nikolov, et al, 2009; McElhanon et al, 2014).

Approximately, $36 \%$ of children with ASD had constipation. Although constipation in autistic spectrum disorder is a critical issue, its causes remain embarrassing (Afzal et al., 2003). However, there are numerous suggested explanations such as inherited gut abnormality, the neurotoxic bacteria, and serotonin abnormalities. Other studies claimed that constipation in autistic spectrum disorder is related to the food selectivity feature of autistic children that result in restrictive diets and low fibre intake (Ibrahim et al., 2009; Maenner et al., 2012).

Constipation has negative consequences on the children include abdominal distension, discomfort, pain, anorexia, malaise and angry mood (National Collaborating Centre for Women's and Children's Health-UK, 2010). In addition, straining during defection may result in faecal impaction, haemorrhoids (Potter and Perry, 2001). 
Indeed, it increases the rate of children hospitalization and thought to have influences on the children behaviours and brain functions (Nikolov et al, 2009). For these reasons, children with autism require innovative and less disturbing nursing intervention to manage constipation. Reflexology is a widely used technique and documented as a useful nursing intervention (Woodward, Norton \& Barriball, 2010; Lee et al., 2011).

Feet reflexology is the application of appropriate hand and finger pressure to specific points on the feet called reflex sites (Jones et al., 2013). Those reflex sites are believed to be closely related to the internal organs of the body (Dane and Welcome, 2018). The mechanism of feet reflexology still unclear, however, evidence proposed that feet reflexology regulates the autonomic nervous system equilibrium (Arslan et al., 2014; Isik et al., 2015) and increases the blood supply to the projected organs (Jones et al., 2013).

Reflexology is a safe, efficient, and reliable technique that has no reported side effects. It is an ancient healing art of holistic non-invasive pressure and touches therapy (Xavier, 2007). Feet reflexology considered beneficial alternative treatment in relieving headache, fatigue, pain, insomnia, anxiety, menstrual disorders, arthritis, and digestive problems (Cade, 2002; Omer, 2004; Xavier, 2007; Close, McCullough, Sinclair, Liddle \& Hughes, 2015). For children with developmental disabilities particularly autism, it improves early childhood development ((Maulik \& Darmstadt, 2009; Silva, Schalack \& Gabrielsen, 2011).

Paediatric nurses assume a crucial role in helping autistic children and their parents for determination of goals that facilitate appropriate nursing intervention (Wallace, 2010). Above all, there is a lack of researches in the area of reflexology applied to children particularly autistic children. Therefore, this study was conducted to determine the effect of feet reflexology on autism symptoms and constipation in children with ASD.

\subsection{The Purpose of the Study}

This study aimed to determine the effect of foot reflexology on autism symptoms and constipation in children with ASD.

\subsection{Hypothesises}

- Autistic children who would receive foot reflexology would exhibit improvement in autism symptoms.

- Autistic children who would receive foot reflexology would exhibit low constipation severity.

\section{Subjects and Methods}

\subsection{Research Design}

The researcher utilized a quasi-experimental design to conduct this study.

\subsection{Research Setting}

This study was conducted at the psychiatric outpatient clinic, Menoufia University hospital at Shebin El-Kom city.

\subsection{Participants:}

A purposive sample of 40 children was recruited. The sample size was determined based on the study of Fraenkel \& Wallen (2003). They recommended 30 participants for quiz experimental study design. For selecting purposes, all children who met the following criteria were invited to participate in the study.

\section{A. Inclusion criteria:}

1. Confirmed diagnose of ASD

2. Aged ranged from 2-18 years.

3. Willing of parents to participate

B. Exclusion criteria: All children who had one or more of the following conditions were excluded from the study sample.

1. Feet eczema

2. Diarrhoea, vomiting, fever

3. Untreated severe medical conditions

\section{a. Instruments}

For data collection purpose, the researcher utilized two instruments.

Instrument one: Autism Treatment Evaluation Checklist (ATEC). It developed by Rimland and Edelson (1999) to assess changes in autism symptoms. This tool was divided into two parts.

Part one: Socio-demographic characteristics of autistic children to obtain data such as children's age, sex, and diagnosis.

Part two: Autism Treatment Evaluation Checklist (ATEC). It included 77 statements distributed into four subscales. The first subscale speech/language/communication (14 statements), sociability subscale (20 statements), sensory/cognitive awareness (18 statements) and health/physical/behavior ( 25 statements). Scores of each statement ranged from zero to two except for those of the health/physical/behavior subscale. It ranged from 0-3. The total score of ATEC subscales ranged from 0-179 points. Scoring system of ATEC: 


\begin{tabular}{|c|c|c|c|}
\hline Degree of Severity & Mild & Moderate & Severe \\
\hline Score Ranges & $20-49$ & $50-79$ & $\geq 80$ \\
\hline
\end{tabular}

The reliability of the ATEC tool was confirmed by Cronbach's Alpha test $(r=0.91)$.

Instrument Two: Constipation Assessment Questionnaire (CAQ). It adapted from Pediatric Constipation Assessment scale and Bristol Constipation Chart (BCC) (Woorely, et al., 2004) then modified by the researcher. It included two parts.

Part one: It is a five-point Likert scale included 20 items to assess the presence and severity of constipation (stool frequency, consistency, straining, and painful passage). It ranged from almost never to almost always. The total score ranged from 0-100 points. Scoring system of CAQ:

\begin{tabular}{|c|c|c|c|c|}
\hline Degree of Severity & No constipation & Mild & Moderate & Severe \\
\hline Score Ranges & $\leq 20$ & $>20-39$ & $40-60$ & $>60$ \\
\hline
\end{tabular}

Part two: Daily habits assessment sheet to assess children mobility, fluid, fiber, and medication intakes.

The reliability of the tool was reported by Cronbach's Alpha test $r=0.80$.

\subsection{Validity and Reliability:}

Tools were developed by the researcher for data collection after a review of past and current literature, local and international related literature using books, articles, periodicals, and magazines. Then, the tools were submitted to a panel of three pediatric nursing experts for the validity purpose. Tools reliability was tested by Cronbach's coefficiency alpha.

\subsection{Ethical Consideration:}

For the protection of human rights, the researchers obtained informed consent from the third year pediatric nursing students after a clear explanation of the objectives of the study, its importance, safety and confidentiality for the participants.

\subsection{Pilot study:}

A pilot study was carried out on 10 students to test the practicability, applicability, and feasibility of items in data collection tools. No modifications were done. The sample of the pilot study was excluded from the total sample.

\subsection{Procedure:-}

1. Prior to data collection, written permission to carry out the study was obtained from the manager of the Menoufia University hospital after explaining the purpose of the study and methods of data collection.

2. Data was collected over a period of 13 months began in July 2017 and ended on August 2018.

3. The researcher performed feet reflexology sessions once per week over a period of six weeks. Each session lasted for 30 minutes (15 minutes for each foot).

4. The researchers conducted the study on three phases (preparatory, performance and evaluation).

\section{A. Preparatory phase}

i. The researcher attended a reflexology training program and earned a reflexology practitioner certificate.

ii. The researchers selected an appropriate photo gallery on feet reflexology to clarify its zones for parents.

iii. During the initial meeting with parents, the researchers explained the procedure of feet reflexology and its benefits. Once they agreed to participate in the study, the researcher began collecting baseline data using the study instruments.

iv. The researcher instructed parents that the session would take place before meals or 2 hours after meals.

\section{B. Performance phase}

i. Prior to each feet reflexology session; the researcher inspected the child's feet for any abnormality and performed feet care if required.

ii. The researcher utilized baby oil to facilitate appropriate thumb and finger pressure technique.

iii. The researcher began the procedure of feet reflexology by mapping the feet for upper and lower digestive reflex. It included areas of the sole at diaphragm reflex zone corresponding to stomach, pancreas, and spleen in the left foot and liver and gallbladder in the right foot. Meanwhile, at the waist reflex zone, there were ascending, transverse and descending colons as well as small intestine areas at both of the feet. Finally, sigmoid colon at the pelvic zone.

iv. The researcher applied thumb pressure with angle of $90^{\circ}$ to the predetermined areas of the sole following the direction from $5^{\text {th }}$ vertical/toe zone toward the $3^{\text {rd }}$ vertical/toe zone.

v. The researcher applied thumb pressure for 3 times for each area starting in horizontal lines then from down to upward vertically.

vi. The same technique was applied to the right and left feet

C. Evaluation Phase:

D. At the end of the $6^{\text {th }}$ week, the researcher re-assessed the children's autism symptoms and constipation 
by the study instruments.

\subsection{Statistical Analysis:}

The collected data were categorized, tabulated, and summarized. Data were computerized and analyzed by SPSS version 20 (SPSS Inc., Chicago, IL, USA). Two types of statistics were done descriptive and analytical to examine the research hypothesis. Descriptive statistics were done using percentage (\%), mean and standard deviation (SD). Analytical statistics used in the study were Chi-Squared $\left(\chi^{2}\right)$, ANOVA test and Pearson correlation test. Statistically, a significant difference was found if $\mathrm{P}<0.05$.

Limitation of the study: A number of 10 children were discontinuing the feet reflexology sessions more than four sessions and they were excluded from the statistical analysis.

\section{Results}

Table1: Characteristics of studied children with ASD.

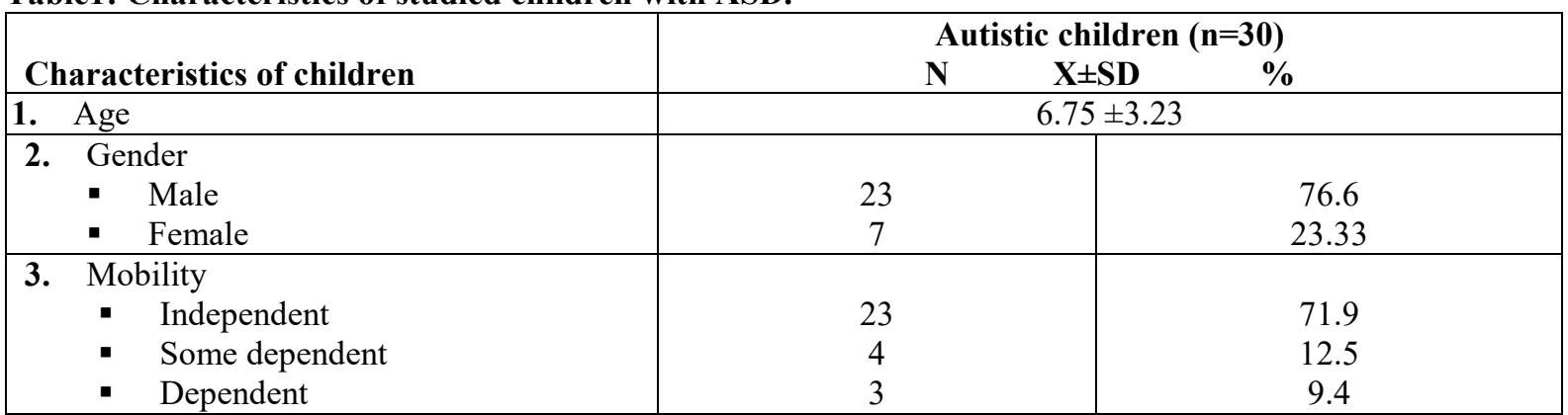

Table 1 showed the characteristics of children with autism. It was obvious from this table that the mean of children age was $6.75 \pm 3.23$. Regarding their gender, the majority of children $(76.6 \%)$ were male. In relation to mobility, $71.9 \%$ of them were independent.

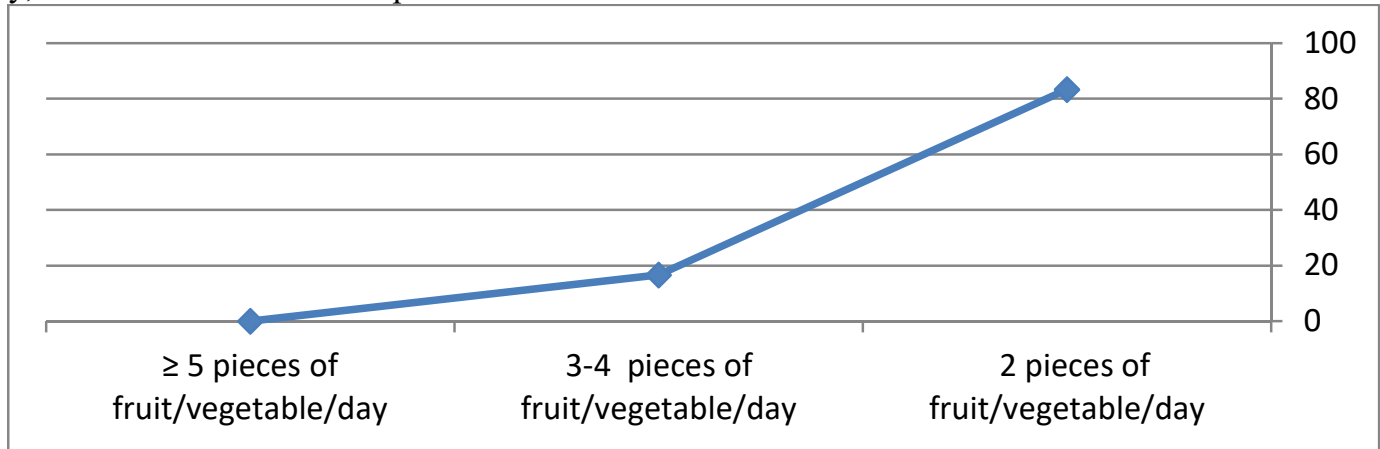

Figure1: Distribution of fiber intake among children with ASD.

Figure 1 represented the distribution of fiber intake among children with ASD. It clarified that the majority of children $(83.33 \%)$ consumed 2 pieces of fruit/vegetable/day.

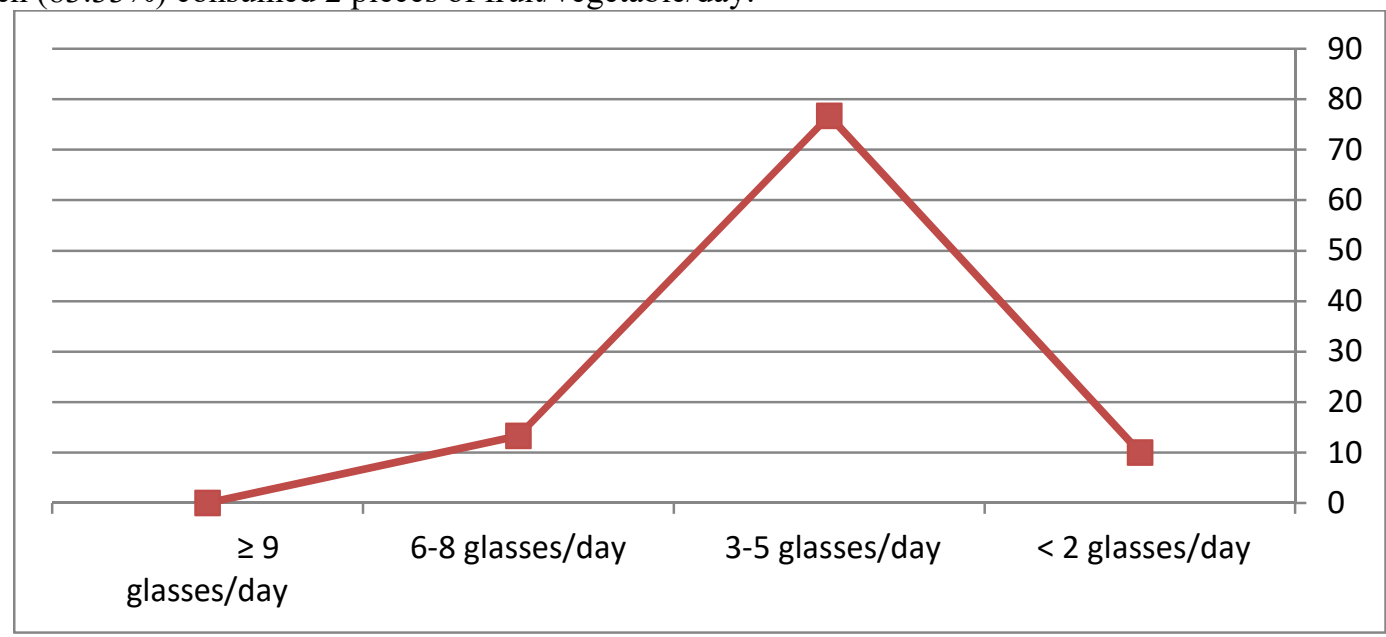

Figure2: Distribution of fluid intake among children with ASD.

Figure 2 showed the distribution of fluid intake among children with ASD. It clarified that the majority of children (76.7\%) drank 3-5 glasses/day. 
Table2: Mean and standard deviation of autism symptoms on pre-and post-intervention among children with ASD.

\begin{tabular}{|l|c|c|c|}
\hline \multicolumn{1}{|c|}{ Autism symptoms } & $\begin{array}{c}\text { Pre-intervention } \\
(\mathbf{n = 3 0 )} \\
\mathbf{X} \pm \mathbf{S D}\end{array}$ & $\begin{array}{c}\text { Post-intervention } \\
(\mathbf{n = 3 0 )} \\
\mathbf{X} \pm \mathbf{S D}\end{array}$ & $\mathbf{F}$ \\
\hline Speech/ Communication & $21.07 \pm 3.37$ & $19.50 \pm 3.39$ & $90.86^{* * *}$ \\
\hline Sociability & $10.13 \pm 3.00$ & $9.20 \pm 3.23$ & $77.28^{* * *}$ \\
\hline Sensory/ Cognitive & $12.97 \pm 5.37$ & $11.96 \pm 5.38$ & $126.92^{* * *}$ \\
\hline Health/Physical/ Behavior & $22.30 \pm 6.11$ & $20.50 \pm 5.63$ & $130.84^{* * *}$ \\
\hline \multicolumn{1}{|r|}{ Total } & $66.30 \pm 16.80$ & $61.07 \pm 16.44$ & $86.19^{* * *}$ \\
\hline
\end{tabular}

${ }^{*}$ Highly statistical significant at $\mathrm{P}<0.001$.

Table2 represented Mean and standard deviation of autism symptoms on pre-intervention and after 6 weeks of feet reflexology. As illustrated in the table, the children had lower mean scores of autism symptoms on postintervention compared to pre-intervention speech/communication, sociability, sensory/cognitive, health/physical/behavior subdomains and the total score $(19.50 \pm 3.39,9.20 \pm 3.23,11.96 \pm 5.38,20.50 \pm 5.63$ and $61.07 \pm 16.44$ respectively). Therefore, there were highly statistically significant differences between children autism symptoms at $1 \%$ level of statistical significance.

Table3: Severity of autism symptoms on pre and post-intervention among children with ASD.

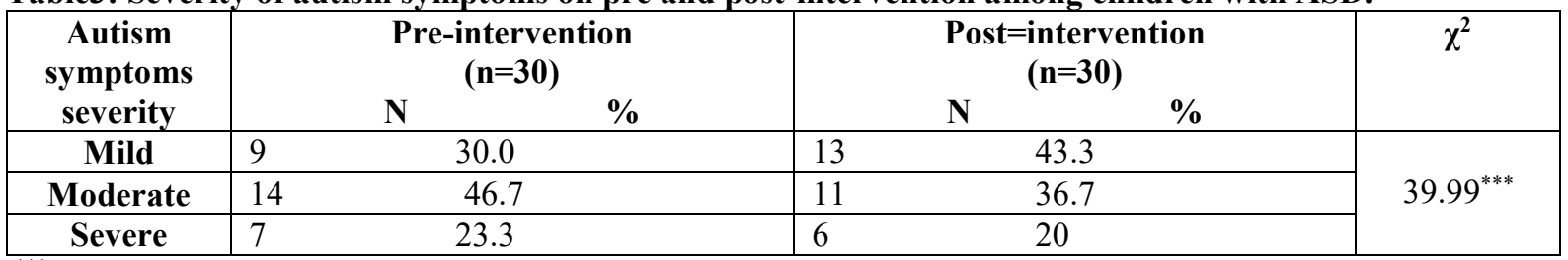

*** Highly statistical significant at $\mathrm{P}<0.001$.

Table3 illustrated the severity of autism symptoms on pre- and post-intervention among children with ASD. It was obvious that there was a lessening in the severity of autism symptoms on post-intervention compared to preintervention (mild $43.3 \%$, moderate $36.7 \%$ and severe $20 \%$ ). Therefore, there were highly statistically significant differences between children regarding the severity of autism symptoms at $1 \%$ level of statistical significance.

Table4: Severity of constipation on pre- and post-intervention among children with ASD.

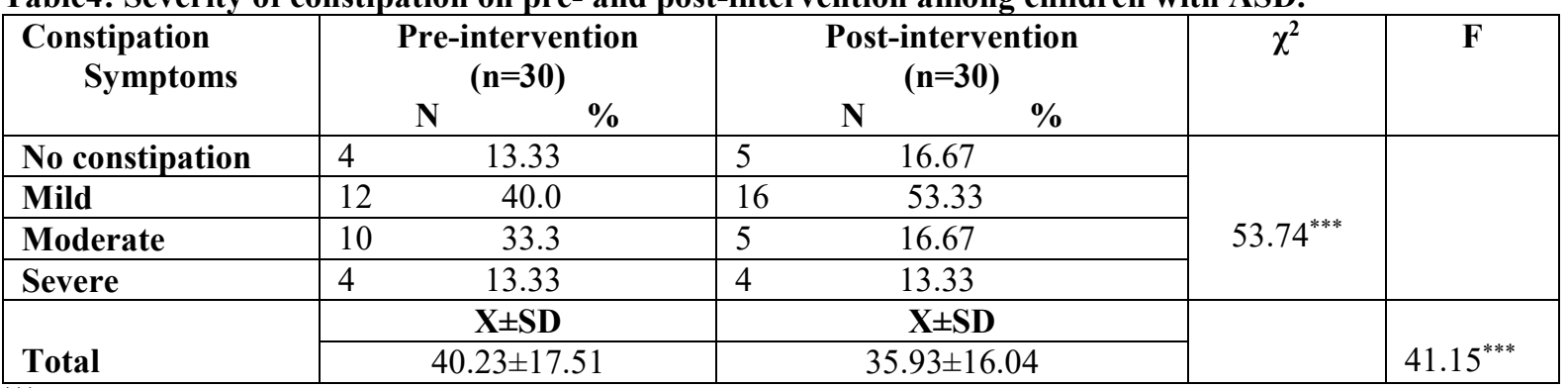

${ }^{* * *}$ Highly statistical significant at $\mathrm{P}<0.001$.

Table4 clarified the severity of constipation on pre and post-intervention among children with ASD. It was clear that children exhibited lower severity of constipation symptoms on post-intervention compared to preintervention (no constipation $16.67 \%$, mild $53.33 \%$ and moderate $16.67 \%$ ). In addition, the mean total score of constipation symptoms was lower on post-intervention compared to pre-intervention $(35.93 \pm 16.04,40.23 \pm 17.51$ respectively). Therefore, there were highly statistically significant differences between children regarding the severity of constipation symptoms at $1 \%$ level of statistical significance. 


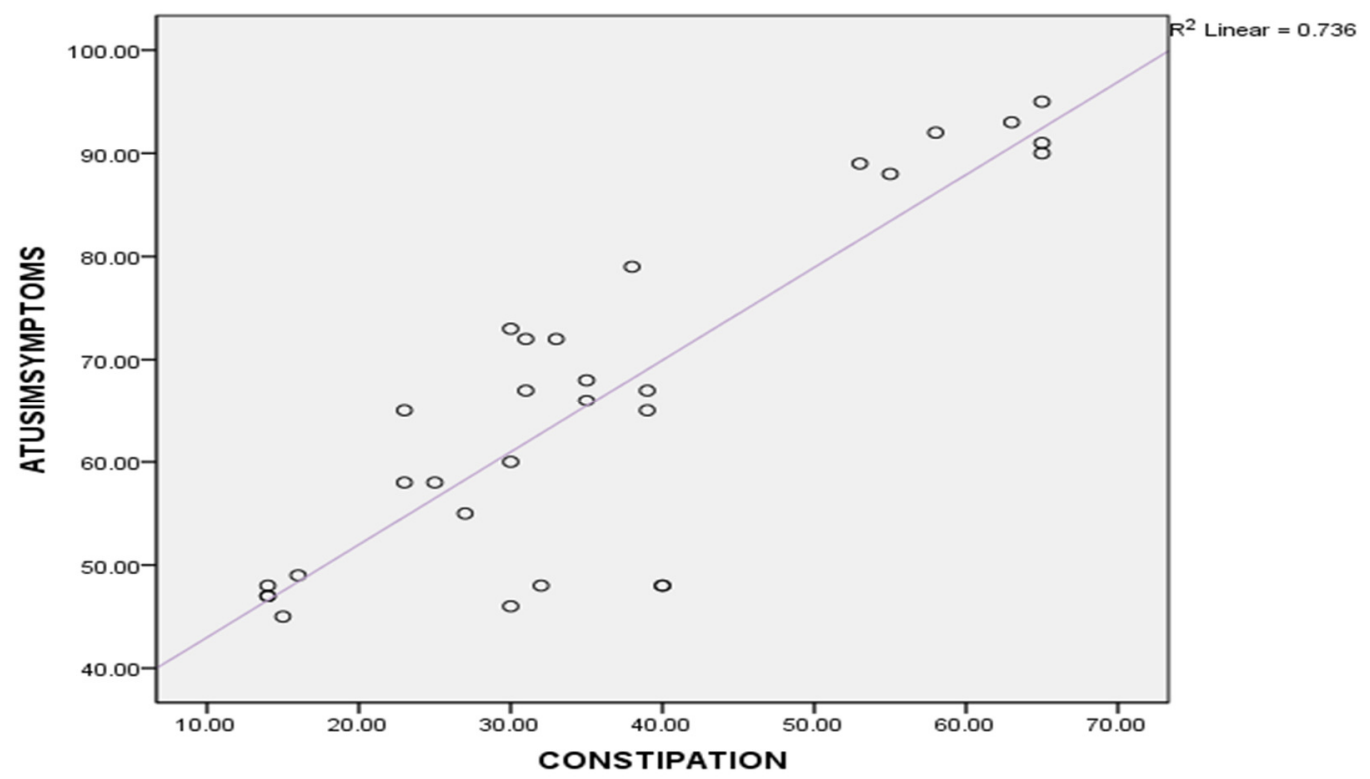

Figure3: Pearson correlation between constipation and severity of autism symptoms on post-intervention.

Figure 3 illustrated the Pearson correlation between constipation and severity of autism symptoms on postintervention. It showed that there was a significant correlation $(\mathrm{R}=0.858)$ at the 0.01 level of significance between constipation and the severity of autism symptoms on post-intervention.

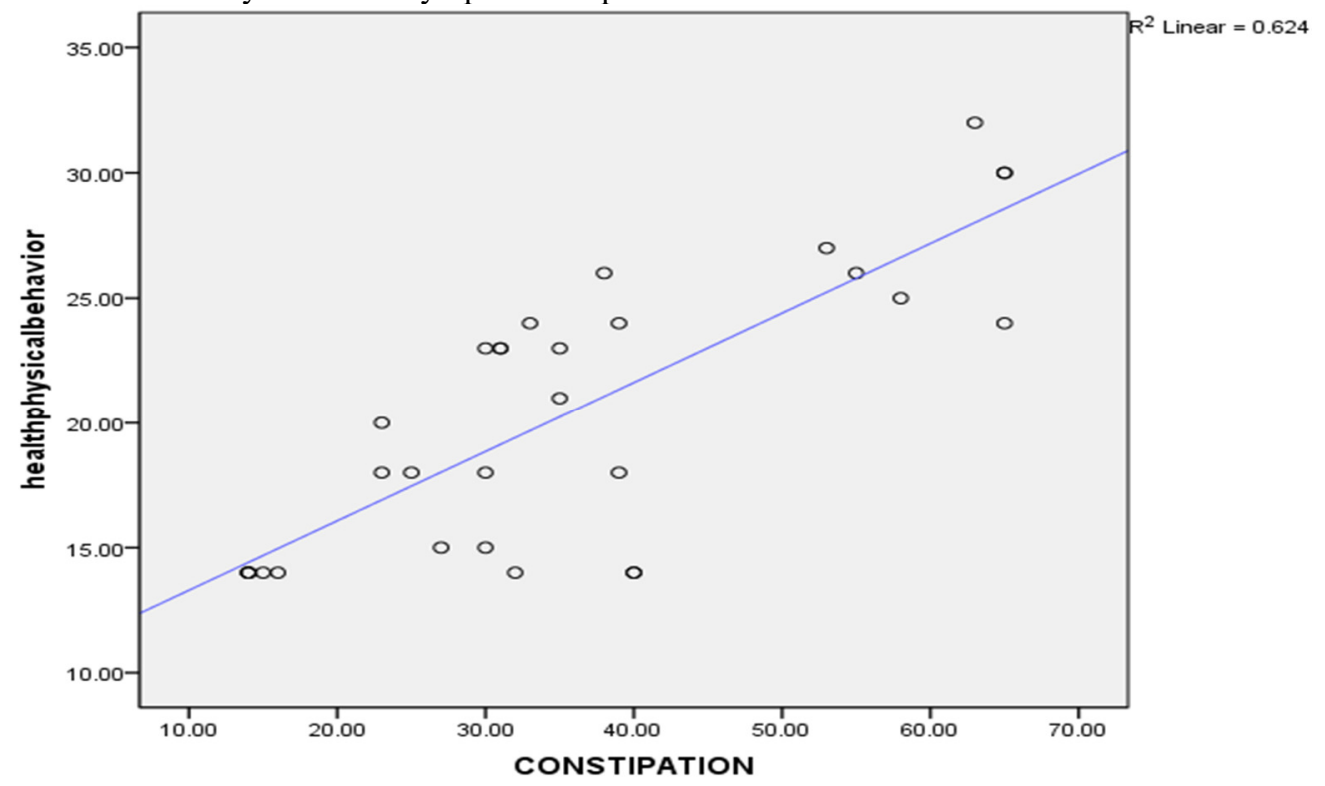

Figure4: Pearson correlation between constipation and health/physical/behavior subdomain of ATEC on post-intervention.

Figure4 showed the Pearson correlation between constipation and health/physical/behavior subdomain of ATEC on post-intervention. It showed that there was a significant correlation $(\mathrm{R}=0.858)$ at the 0.01 level of significance between constipation and health/physical/behavior subdomain of ATEC on post-intervention.

\section{Discussion}

Owing to the various health problems that coexist with Autistic Spectrum Disorders, it presents challenges for children's health. One of the most common issues associated with autism is gastrointestinal problems particularly, constipation which results in further distress on children (Afzal et al., 2003; Ibrahim et al., 2009). Feet reflexology as a simple and useful procedure may provide satisfactory outcomes for constipation (Stephenson and Dalton, 2003). This study hypothesized that autistic children who would receive feet reflexology would exhibit improvement in autism symptoms and low constipation severity.

In this study, the majority of children were males; most of them drank 3-5 glasses/day and consumed 2 pieces of fruit/vegetable/day. A previous study (Newschaffer et al., 2007) which evaluated the epidemiology of autism 
spectrum disorders similarly, showed that autism is more prevalent among boys than girls. In addition, Mahapatra et al., (2018) found in their study "Longitudinal Epidemiological Study of Autism Subgroups Using ATEC Score" that $83 \%$ of children with autism were males. The children showed decreased consumption of fluid and fiber intake which predisposed them for another risk factor for constipation regardless of their mobility.

In relation to the hypothesis of the current study, the findings confirmed that autistic children who received reflexology sessions exhibited a significant improvement of constipation compared to pre-intervention. Improvement included stool frequency, consistency, and straining. These findings are congruent with those of Bishop (2003), who examined the effect of "reflexology in the management of encopresis and chronic constipation" in normal children with chronic constipation. She reported a significant increase in the stool frequency after six sessions of reflexology. In addition, increased appetite and improved sleep pattern.

In contrast, Lee et al. (2011) declined in their study any significant effects of reflexology as an intervention for patients with diverse diseases except for its effects on enuresis and did not recommend reflexology. Their point of view was based on the lack of studies and evidence of reflexology efficacy. Contradictorily, with the findings of the current study which asserted the positive effect of reflexology on constipation although the special characteristics of autistic children in addition to the probably inherited tendency of gastrointestinal issues with autism.

It is worth mentioning that during the search in the previous studies concerning the reflexology as an alternative intervention method for constipation in children, there was only one study done by Bishop. However, there were various studies confirmed the positive effects of reflexology on constipation. Guiling (2004) confirmed the benefits of feet reflexology in relieving and preventing constipation among elderly persons. In parallel with Woodward, Norton, and Barriball (2010), they reported the positive effect of reflexology sessions in relieving constipation in old women. A more recent study by Cevik and Zaybak (2018) entitled "The Effect of Reflexology on Constipation in the Elderly" concluded that feet reflexology is an effective nursing intervention achieved desirable positive changes in the symptoms of constipation.

Regarding autism symptoms, the results yielded that autistic child who received reflexology sessions had significantly lower mean scores of autism symptoms compared to pre-intervention. It included the total score of ATEC and the four subdomains (speech/communication, sociability, sensory/cognitive, health/physical/behavior). In addition, the severity of autism symptoms was significantly lowered. The researcher attributed these findings to the reported benefits of reflexology which include relieving pain, decrease sleep problems, eliminate toxins, regulate nerve functions, promote circulation, improve appetite, increase concentration and improve mood (Hodgson 2000; Center for Spirituality \& Healing and Charlson Meadows, 2015).

Consequently, functions of neurologic and digestive systems improved which are closely linked to frequent symptoms associated with autistic children. In other words, regulating the internal systems is reflected with improved communication, sociability, cognitive, physical and behavioral skills. This point of view is supported by the findings of Adams et al., (2011) who mentioned in his study that children with gastrointestinal symptoms exhibit serious behaviors.

Furthermore, the current study revealed that there is a significant correlation between the severity of constipation and autism symptoms. In addition, Chaidez et al., (2014) found a correlation between gastrointestinal problems and maladaptive behavior in children with autism. In agreement, with the findings of Wang et al., (2011), they documented that the more severity of gastrointestinal problems, the more severity of autism symptoms

Moreover, searching the literature for previous studies conducted on reflexology and its' effect on autism symptoms, the researcher did not find studies on this topic. Therefore, the current study considered the first. There is, however, frequent studies examined the effect of massage therapy on autism symptoms regardless of its type. Escalona et al., (2001) stated that following massage therapy, autistic children exhibited social relatedness behavior and fewer sleep problems, Lee et al. (2011) added that applying deep pressure massage can improve behavioral and cognitive symptoms of ASD. In addition, Walsh supposed that all children need tactile sensory stimulation. Therefore, the current study proved that foot reflexology has positive effects on autism symptoms and constipation in children with the autistic spectrum disorder.

\section{Conclusion:}

The study concluded that autistic children exposed to feet reflexology experienced lower mean scores of autism symptoms and less severity of constipation compared to pre reflexology massage. There was a significant correlation between constipation and the severity of autism symptoms.

\section{Recommendation:}

1. Feet reflexology should be integrated as a part of routine daily care for autistic children.

2. Courses that enable nurses to obtain a certification in reflexology are needed.

3. Further researcher on a wide range of sample to ensure the generalizability of the results. 


\section{References}

[ 1] Adams, J.B., Johansen, LJ, Powell, L.D., et al. (2011). Gastrointestinal flora and gastrointestinal status in children with autism-comparisons to typical children and correlation with autism severity. BMC Gastroenterol; 11:22.

[ 2] Afzal N, Murch S, Thirrupathy K, Berger L, Fagbemi A, Heuschkel, R. (2003). Constipation with acquired megarectum in children with autism. Pediatrics; 112(4):939-942.

[3] American Psychiatric Association (2013), Diagnostic and Statistical Manual of Mental Disorders, fifth ed., American Psychiatric Association, Arlington, VA, USA.

[ 4] Arslan, M., yesileam, N., aydin, D., yuksel, R., Dane, S. (2014). Wet cupping therapy restores sympathovagal imbalances in cardiac rhythm. J. Alternative Compl. Med. 20.

[ 5] Baio, J., Wiggins, L., Christensen, D. L., Maenner, M. J., Daniels, J., Warren, Z., et al. (2018). Prevalence of autism spectrum disorder among children ages years-Autism and developmental disabilities monitoring network, 11 sites, United States, 2014. MWWR Surveillance Summary, 67, 1-23.

[6] Bishop, E., McKinnon, E., and Weir, E. (2003). Reflexology in the management of encopresis and chronic constipation. Paediatric Nursing; Harrow on the Hill; Apr; 15(3):20-1

[7] Buie T, Campbell DB, Fuchs GJ, et al. (2010). Evaluation, diagnosis, and treatment of gastrointestinal disorders in individuals with ASDs: a consensus report. Pediatrics;125(Suppl 1):S1-8.

[ 8] Cade M. (2002). Reflexology. Kansas Nurse, 77, 5-7.

[9] Cevik, K. and Zaybak, A. (2018). The Effect of Reflexology on Constipation in the Elderly. International Journal of Caring Sciences. January-April; (1)11:309.

[ 10]Chaidez, V., Hansen, R., and Hertz-Picciotto, I. (2014). Gastrointestinal problems in children with autism, developmental delays or typical development. J Autism Dev Disord. May; 44(5): 1117-1127.

[ 11]Close C., McCullough J., Sinclair M., Liddle D., Hughes C. (2015). A Pilot Randomised Controlled Trial (RCT) investigating the effectiveness of reflexology for managing pregnancy low back and pelvic pain. Complementary Therapies in Clinical Practice, S1744-3881(15), 00041-00049. doi:10.1016/j.ctcp.2015.05.002.

[12]Dan, S., and Welcome, O. M. A case Study: Effects of foot reflexology on ADHD symptoms and enuresis nocturia in a child with ADHD and enuresis nocturia. Complementary Therapies in Clinical Practice; 33 (2018) 139-141.

[ 13]Elbahnasawy, H., Girgis, N M. (2011). Counseling for Mothers to Cope with their Autistic Children. Journal of American Science; 7(7).

[ 14]Escalona, A., Field, T., Singer-Strunck, R. et al. J Autism Dev Disord (2001) 31: 513.Rimland, B.; Edelson, S. Autism Research Institute. Autism Treatment Evaluation checklist (ATEC) 1999.

[ 15]Fletcher PC, Markoulakis R, Bryden PJ. The costs of caring for a child with an autism spectrum disorder. Issues Compr Pediatr Nurs. 2012;35(1):4569pmid:22250966

[ 16]Fraenkel, J. R. \& Wallen, N. E. (2003). How to design and evaluate research in education. Fifth ed. New York: McGraw-Hill.

[ 17] Ghoneim AA. Health Promotion Toolkit: An Approach for Empowering Families Caring for Children with Developmental Disabilities in Tabuk. Open Access Maced J Med Sci. 2018 Aug 5;6(8):1503-1511. Doi: 10.3889/oamjms.2018.265.ecollection 2018 Aug 20.

[18]Guiling S. (2004). Treatment and prevention of constipation by reflexotherapy. China Symposium Reflexology Report; 55-58. Available at: http://www.reflexologyresearch.net/Reflexology ConstipationResearch3.shtml. Accessed: 8.05.2013.

[ 19]Haffiz, M. (2007). Study about Problem Size of Autism in Egypt. Pediatric Medicine, National Commission for Childhood, Studies and Research Forum, P, 7 and 78.

[ 20]Hockenberry, M. J. and Welson, D. (2013). Wong's essentials of pediatric nursing, 9th ed., Mosby, an imprint of el Sevier inc. USA, PP. 590-595.

[ 21]Hodgson, Nancy, A., and Susan Andersen. "The Clinical Efficacy of Reflexology in Nursing Home Residents with Dementia". The Journal of Alternative and Complementary Medicine 14.3(2008):269-275.

[22]Iannuzzi, D., Rissmiller, P., M. Duty, S.M., Feeney, S, Sullivan, M., and Curtin, C. (2018). Addressing a Gap in Healthcare Access for Transition-Age Youthwith Autism: A Pilot Educational Intervention for Family Nurse Practitioner Students. JAutism Dev Disord; Dec 8. doi: 10.1007/s10803-018-3846-9.

[23]Ibrahim SH, Voigt RG, Katusic SK, Weaver AL, Barbaresi WJ. (2009) Incidence of gastrointestinal symptoms in children with autism: population-based study. Pediatrics ;124(2):680-686 (Epub 27 Jul 2009).

[ 24]Isik, B., Aydin, D., Arslan, M., Dane, S. (2015). Reflexlogical therapy includes a state of balance in autonomic nervous system, Clin. Invest. Med. (38):244-248.

[25]Jones, J., Thomson, P., Irvine, K., and Leslie, S.J. (2013). Is there a specific hemodynamic effect in reflexology? A systematic review of randomized controlled trials. J Alter Complement Med.; Apr;19(4):31928. doi: 10.1089/acm.2011.0854. 
[ 26] Kotagal S, Broomall E. Sleep in children with autism spectrum disorder. (2012). Pediatr Neurol; 47(4):24251.

[ 27]Lee MS, Kim JI, Ernst E. (2011). Massage therapy for children with autism spectrum disorders: a systematic review. J Clin Psychiatry; 72:406-11.

[ 28] Maenner MJ, Arneson CL, Levy SE, Kirby RS, Nicholas JS, Durkin MS. (2012). Brief Report: Association between behavioral features and gastrointestinal problems among children with autism spectrum disorder. $J$ Autism Dev Disord. ;42:1520-1525.

[ 29] Mahapatra, S., Khokhlovick, E., Martinez, S., Kannel, B., Edenson, S.M., and Vyshedskiy, A.( . 2018 ). Longitudinal Epidemiological Study of Autism Subgroups Using ATEC Score. J Autism Deve Disord; Jul 30. doi: 10.1007/s10803-018-3699-2.

[ 30]Maulik, P. K., \& Darmstadt, G. L. (2009). Community-based interventions to optimize early childhood development inlow resource settings. Journal of Perinatology; 29: 531-542. http://dx.doi.org/10.1038/jp.2009.42.

[ 31] McElhanon, B. O., McCracken, C., Karpen, S., Sharp, W. G. (2014). Gastrointestinal Symptoms in Autism Spectrum Disorder: A Meta-analysis. Pediatrics: May; 133(5).

[ 32]National Collaborating Centre for Women's and Children's Health (UK). (2010). Constipation in Children and Young People Diagnosis and Management of Idiopathic Childhood Constipation in Primary and Secondary Care. NICE Clinical Guidelines; No. 99. Available at: https:/www.ncbi.nlm.nih.gov.

[ 33] Newschaffer CJ, Croen LA, Daniels J, Giarelli E, Grether JK, Levy SE, Mandell DS, Miller LA, Pinto-Martin J, Reaven J, Reynolds AM, Rice CE, Schendel D, Windham GC (2007) The epidemiology of autism spectrum disorders. Annu Rev Public Health; 28:235-258

[ 34]Nikolov RN, Bearss KE, Lettinga J, Erickson C, Rodowski M, Aman MG, et al. (2009). Gastrointestinal symptoms in a sample of children with pervasive developmental disorders. J Autism Dev Disord. ; 39 (3):405-413.

[ 35] Omer, M. (2004). Reflexology: Complete Treatment of the Body through Feet and Hand Massage, 1 st ed. Dar Elkhial.

[ 36]Park H. R., Lee J. M., Moon H. E., Lee D. S., Kim B. N., Kim J., Paek S. H. (2016). A short review on the current understanding of autism spectrum disorders. Experimental Neurobiology; 25(1): 1-13. 10.5607/en.2016.25.1.1.

[ 37]Potter, P., and Perry, A. G. (2001). Fundamentals of Nursing. 5th ed. Mosby, Inc.

[38]Rimland, B., \& Edelson, S. (1999). Autism Treatment Evaluation Checklist (ATEC). San Diego: Autism Research Institute.

[ 39] Silva, L. M., Schalock, M., \& Gabrielsen, K. (2011). Early intervention for autism with a parent-delivered qigong massage program: A randomized controlled trial. American Journal of Occupational Therapy; 65: 550-559. http://dx. doi.org/10.5014/ajot.2011.000661.

[ 40] Stephenson, Nancy L. N., and Jo Ann Dalton. (2003). "Using Reflexology for Pain Management: A Review". Journal of Holistic Nursing; 21( 2): 179-191.

[ 41] The Center for Spirituality \& Healing and Charlson Meadows. (2015, September 25). Reflexology. Available at: http://www.takingcharge.csh.umn.edu/explore-healing-practices/reflexology .

[ 42] Wallace, R. B. (2010). 'Tertiary Prevention' In encyclopedia of Public Health. Available at: http://www.enotes.com/public

[43]Wang, L.W., Tancredi, D.J and Thomas, D.W. (2011).The Prevalence of Gastrointestinal Problems in Children Across the United States With Autism Spectrum Disorders From Families With Multiple Affected Members. J Dev Behav Pediatr; 32:351-360.

[ 44] Woodward S., Norton C. \& Barriball KL. (2010). A pilot study of the effectiveness of reflexology in treating idiopathic constipation in women. Complementary Therapies in Clinical Practice, 16: 41-46.

[ 45] Woorely, M., Carroll, E., Fenn, E., Wielland, H., Jarosinki, P., Corey, B., Wallen, GR. (2006). A constipation assessment scale for use in pediatric oncology. J Pediatr Oncol Nurs. Mar-Apr;23(2):65-74.

[ 46] Xavier R. (2007). Facts on reflexology. Nursing Journal of India, 98, 11-12. 